to both aEEG pattern at $48 \mathrm{~h}$ and MRI performed during the second week. Comparisons were done with ANOVA, SPSS19.

Results 21 newborns were monitored. During hypothermia there was a trend towards higher $\mathrm{rSO}_{2}$ in newborns with predicted abnormal outcome. During rewarming there was a significant difference between the normal and abnormal outcome groups $(p<0.02)$.

Abstract 1069 Table 1 rSO2 values during hypothermia and rewarming

\begin{tabular}{lcccc}
\hline & $\mathbf{r S O}_{\mathbf{2}}$ & Normal $(\mathbf{n}=\mathbf{9})$ & Intermediate $(\mathbf{n}=\mathbf{4})$ & Abnormal $(\mathbf{n}=\mathbf{8})$ \\
\hline Hypothermia & 12 hours & 76,3 & 74,5 & 79,4 \\
& 24 hours & 83,1 & 77,0 & 88,1 \\
& 48 hours & 84,6 & 88,0 & 89,5 \\
\multirow{4}{*}{ Rewarming } & 72 hours & 82,1 & 79,0 & 87,4 \\
& $34.5^{\circ} \mathrm{C}$ & 77,3 & 84,0 & 89,8 \\
& $35.5^{\circ} \mathrm{C}$ & 75,8 & 73,5 & 88,4 \\
& $35.5^{\circ} \mathrm{C}$ & 74,6 & 77,8 & 87,4 \\
\hline
\end{tabular}

Conclusions NIRS monitoring may improve the early recognition of newborns with abnormal outcome. Our data suggests that a $\mathrm{rSO}_{2}$ value of 85 during rewarming can be used as a cutoff for predicting abnormal outcome.

\section{CEREBRAL BLOOD FLOW CHANGES IN PRETERM NEONATES REQUIRING RESUSCITATION AT BIRTH}

doi:10.1136/archdischild-2012-302724.1070

${ }^{1} \mathrm{~N}$ Ahmed, ${ }^{2} \mathrm{~V}$ Sundaram, ${ }^{2} \mathrm{P}$ Kumar. ${ }^{1}$ Neonatology; ${ }^{2}$ PGIMER, Chandigarh, India

Background Hypoxia in the perinatal period causes increase in cerebral blood flow followed by a decrease. CBF data is not available for preterms.

Objectives To study CBF changes in Anterior and Middle cerebral arteries (ACA \& MCA) of asphyxiated preterm neonates $(<34$ weeks).

Setting Level III Neonatal unit in Northern India, PGIMER, Chandigarh.

Subject and Interventions This is a subgroup analysis of a RCT comparing $21 \%$ vs $100 \%$ oxygen for resuscitation. CBF was measured in ACA and MCA at $6 \pm 2,12 \pm 2$ and $24 \pm 4$ hours. Peak systolic velocity (PSV) $\mathrm{cm} / \mathrm{s}$, End diastolic velocity (EDV) $\mathrm{cm} / \mathrm{s}$, Resistance index (RI), Pulsatality index (PI), Systolic diastolic ratio (S/D) and Velocity time integral (VTI) were measured using Philips ultrasonography machine.

Results CBF was measured in 57 neonates. Mean gestation and weight was $31 \pm 1.3$ weeks and $1400 \pm 358$ g. HIE was seen in 24 babies (42\%). PSV and VTI showed an increasing trend whereas $\mathrm{S} / \mathrm{D}$ showed a decreasing trend as age increased. PSV [29.2 (23.734.2), $28.3(23.9-33.4)$ and $33.9(29.6-37.8) \mathrm{cm} / \mathrm{s}, \mathrm{p}=0.02)$, VTI (6, 6.5 and $8 \mathrm{~cm}, \mathrm{p}=0.002)$ and S/D (4.1 (3.07-6.6), 4.03 (3.3-5.4) and $3.8(3.1-4.7), p=0.01)$ in the MCA showed significant trend at 6,12 and 24 hrs respectively. No such trend could be observed in the ACA. On comparing $21 \%$ and $100 \%$ oxygen groups no difference were observed.

Conclusion CBF indices (PSV, VTI \& S/D) of MCA showed a significant increase from 6 to 24 hrs. No difference was observed on comparing $21 \%$ with $100 \%$ oxygen.

\section{AEEG DURING THE FIRST 72 HOURS AFTER BIRTH IN INFANTS WITH PRENATALLY DIAGNOSED CONGENITAL HEART DEFECT}

doi:10.1136/archdischild-2012-302724.1071

${ }^{1} \mathrm{H}$ ter Horst, 'G Benus, ${ }^{2} \mathrm{M}$ Roofthooft, 'E Kooi, 'A Bos. 'Pediatrics; ${ }^{2}$ Pediatric Cardiology, University Medical Center Groningen, Groningen, The Netherlands
Background and Objective Survival in infants with congenital heart defects (CHD) is associated with neurologic morbidity. Hypoxic-ischemia after closure of the ductus arteriosus is probably one of the factors resulting in brain damage. Prenatal diagnosis makes it possible to prevent closure of the ductus arteriosus and therefore cerebral perfusion can be preserved. Amplitude integrated EEG (aEEG) is a method to evaluate brain injury. Abnormal (a)EEG patterns and epileptic activity (EA) are frequently observed in infants with CHD. Our aim was to determine the course of aEEG patterns in infants with prenatally diagnosed CHD.

Methods Retrospective cohort study of infants prenatally diagnosed with CHD. aEEGs were assessed by pattern recognition: background pattern (BP), presence of sleep wake cycling (SWC) and EA were appraised.

Results Twenty infants (mean GA 39 wks; birth weight 3416 g) were included. Eleven infants had transposition of the great arteries, 7 infants had hypoplastic left heart syndrome, and 2 had aortic valve stenosis. At $6 \mathrm{~h}$ after birth $80 \%$ of infants had normal BPs (continuous normal voltage (CNV)). Only 2 infants had severely abnormal BPs (continuous low voltage). At $24 \mathrm{~h}, 94 \%$ had CNV. None of the infants showed EA. SWC was present in $85 \%$ and emerged at a median postnatal age of $10.4 \mathrm{hrs}$.

Conclusions aEEGs of infants with a prenatally diagnosed CHD are normal in the majority of infants, with normal emergence of SWC and absence of EA. This indicates that prenatal diagnosis can prevent brain damage in infants with $\mathrm{CHD}$

\section{REVIEW OF CURRENT OPINION AND AVAILABILITY OF CEREBRAL FUNCTION MONITORING AND THERAPEUTIC HYPOTHERMIA IN UK NEONATAL UNITS}

doi:10.1136/archdischild-2012-302724.1072

${ }^{1} \mathrm{CS}$ Zipitis, 'A Sylvan, ${ }^{2} \mathrm{~T}$ Harte, ${ }^{1} \mathrm{~S}$ Hurst, ${ }^{1} \mathrm{~K}$ Glover. ${ }^{1}$ Royal Albert Edward Infirmary, Wigan; ${ }^{2}$ Salford Royal Hospital NHS Foundation Trust, Salford, UK

Background and Aims Therapeutic hypothermia has been established as an effective treatment modality for term neonates that have suffered an acute perinatal hypoxic ischaemic event. This is a time-critical procedure which increases pressure to commence active cooling as soon as possible after the injury.

This study aims to define the current levels of ownership of CFM and cooling equipment and capture some staff perceptions around cooling matters in neonatal units in the UK.

Methods Telephone survey conducted over March-November 2011 with the 205 active neonatal units listed on the British Association of Perinatal Medicine website.

Results 100\% response-rate (205/205). 141 (68.8\%) responders were Lead Nurse/Sisters, 59 (28.8\%) were Nurses and 5 (2.4\%) were Doctors. Overall, CFM was available at 106/205 (51.7\%) units and 89/205 (43.4\%) had cooling equipment. Equipment ownership was high in NICUs and progressively decreased in LNUs and SCBUs. The majority of responders were positive to the idea of therapeutic hypothermia as a standard of care whilst some asked for further research; only a small minority were negative. $91.6 \%$ were keen to consider a scheme where therapeutic hypothermia was initiated at the referring centre and continued in a dedicated cooling centre.

Conclusions Therapeutic hypothermia is widely recognised as effective. Availability of cooling equipment and CFM has increased in all levels of units in the UK. The time-constraints in initiating therapeutic hypothermia might mean that a scheme of initiating therapeutic hypothermia locally, continuing this during transport and completing it in a designated cooling centre is the way forward.

\section{EARLY EEG IN INFANTS WITH HYPOXIC ISCAEMIC ENCEPHALOPATHY: POSSIBLE INFLUENCES OF THERAPEUTIC HYPOTHERMIA}

doi:10.1136/archdischild-2012-302724.1073 
'C Llewellyn, ${ }^{2}$ A Kapetanakis, 'S Goyal. 'Electrophysiology; ${ }^{2}$ Neonatal Medicine, Evelina Children's Hospital Guy's and St Thomas' Hospital NHS Foundation Trust, Kings Health Partners, London, UK

Introduction Therapeutic Hypothermia (TH) is an effective neuroprotective treatment for infants with HIE. EEG remains a valuable tool that can that could assist refining neurocritical care and aid in prognosis. The impact of TH on EEG has not been elucidated.

Aim Identify any differences in EEG characteristics caused by $\mathrm{TH}$ in infants with Grade 2 and 3 HIE.

Methods Comparison of EEG characteristics (inter burst interval, EEG grade and prognosis) in infants treated with TH compared to infants treated before TH established as standard treatment.

Results see Table.

Conclusions There are apparent subtle differences in the EEG characteristics of infants receiving $\mathrm{TH}$ compared to non cooled infants. The significance of these differences need to be further studied to improve our understanding of the TH effects.

\section{VENTRICULAR INDEX REMAINS STATIC BETWEEN 24 AND 34 WEEKS}

doi:10.1136/archdischild-2012-302724.1074

${ }^{1} \mathrm{R}$ Gnanasakaran, ${ }^{1} \mathrm{R}$ Shim, ${ }^{2 \mathrm{M}}$ Boyle, ${ }^{3} \mathrm{~A}$ Tarrant, ${ }^{3} \mathrm{~S}$ Ryan, ${ }^{4} \mathrm{~N}$ McCallion. ${ }^{1}$ Department of Paediatrics, RCSI; ' 2 Department of Paediatrics; ${ }^{3}$ Dept of Radiololgy, Rotunda Hospital; ${ }^{4}$ Department of Paediatrics, Rotunda Hospital/Royal College of Surgeons in Ireland, Dublin, Ireland

Background Intraventricular hemorrhage (IVH) and Post Hemorrhagic Ventricular Dilation (PVHD) are serious complications in premature infants and are associated with a high risk of disability. These conditions can be diagnosed by measuring the ratio of ventricular size to overall hemisphere width using Ventricular Index (VI), which was designed for use in infants $>40$ weeks gestation.

Aim To establish Normal Ranges and Median Values for VI.

Method The Ventricular sizes of cranial ultrasounds of infants with a Gestational age at Scan under 34 weeks were assessed using
VI. Ultrasounds with Grade III or IV IVH or PVL were excluded from the study. Ventricular index was measured.

Results From 255 infants, 816 cranial ultrasounds were reviewed. The Normal ranges for LVI were $0-0.69$ and RVI were $0.23-0.88$. The Median Values for both LVI and RVI are 0.31 overall and there was no significant change with increasing gestational age.

Conclusion The Median Values for VI did not significantly change with Gestational Age at scan, and it is appropriate to use the same reference ranges for gestation across all gestation.

\section{RISK FACTORS FOR POSTHEMORRHAGIC HYDROCEPHALUS IN A NEONATAL INTENSIVE CARE UNIT}

doi:10.1136/archdischild-2012-302724.1075

${ }^{1} \mathrm{~F}$ Kulalı, ' $\mathrm{N}$ Altuntas, 'E Kazancl, ${ }^{1} \mathrm{~S}$ Aktas, 'S Unal, 'I Hirfanoglu, 'E Onal, ' $\mathrm{C}$ Turkylmaz, ${ }^{1} \mathrm{E}$ Koc, 'Y Atalay, ${ }^{1} \mathrm{E}$ Ergenekon, ${ }^{2} \mathrm{~K}$ Gucuyener. ${ }^{1}$ Pediatrics/Newborn Medicine; 2Pediatrics, Pediatric Neurology, Gazi University Hospital, Ankara, Turkey

Background and Aim Post-hemorrhagic hydrocephalus (PHH) is one of the most serious complications of intraventricular hemorrhage (IVH) in a newborn. Causes are multifactorial including genetical, pre and postnatal complications. Conditions assosciated with hydrocephalus following IVH were investigated.

Methods Charts of patients admitted to the neonatal intensive care unit (NICU) over last 5 years were investigated retrospectively, newborns with grade 3-4 IVH were analyzed for risk factors in the perinatal and neonatal period. Ones with and without hydrocephalus were compared. Results are expressed as median and range and percentage where required.

Results 24 newborns were diagnosed with IVH, 9 of whom developed hydrocephalus. Most significant risk factors are shown in table 1.

Hypotension, asidosis, were more frequent in the $\mathrm{PHH}$ group. GA, BW, Apgar scores, lowest-highest $\mathrm{CO}_{2}$, Crib score are shown in table 2 .

Highest $\mathrm{CO}_{2}$ in the first 10 days of life was significantly higher in the PHH group ( $\mathrm{p}=0.044)$.

Abstract 1073 Table 1 EEG Findings

\begin{tabular}{|c|c|c|}
\hline & Non cooled Group & TH group \\
\hline Total patients & 13 & 16 \\
\hline Interburst Interval $<20$ & $43.7 \%$ & $54 \%$ \\
\hline Patients withHIE 2 & 7 & 7 \\
\hline EEG grade & Mild: $14.2 \%(n=1)$ Moderate: $71.4 \%(n=7)$, Severe: $14.2 \%(n=1)$ & Mild: $42.8 \%(n=3)$ Moderate: $42.8 \%(n=3)$, Severe $14.2 \%(n=1)$ \\
\hline EEG Prognosis & Good: $14.2 \%$, Guarded: $14.2 \%$, Poor: $71.4 \%$ & Good: $42.8 \%$, Guarded: $14.2 \%$, Poor: $42.8 \%$ \\
\hline Patients withHIE 3 & 9 & 6 \\
\hline EEG grade & $\begin{array}{l}\text { Mild: } 0 \%(n=1) \text { Moderate: } 11.1 \%(n=1) \text {, Severe } 88.9 \%(n=8) \text {, } \\
\text { inactive:0 }\end{array}$ & $\begin{array}{l}\text { Mild: } 0 \%(n=1) \text { Moderate: } 16.6 \%(n=1) \text {, Severe } 16.6 \%(n=1) \text {, } \\
\text { inactive: } 66.6 \%(n=4)\end{array}$ \\
\hline EEG Prognosis & Good: 0\%, Guarded:22.2\%, Poor:77.7\% & Good: 0\%, Guarded: 16.7\%, Poor: 83.3\% \\
\hline
\end{tabular}

Abstract 1075 Table 1

\begin{tabular}{|c|c|c|c|c|c|c|c|c|}
\hline & Female(\%) & Male (\%) & PPV in DR (\%) & Asidosis (\%) & Hypercarbia (\%) & Hypotension (\%) & Pneumothorax (\%) & Low PIt (\%) \\
\hline $\mathrm{PHH}(+) n=9$ & 44 & 56 & 44 & 78 & 78 & 78 & 11 & 66 \\
\hline $\mathrm{PHH}(-) n=16$ & 31 & 69 & 32 & 37 & 44 & 44 & 25 & 62 \\
\hline
\end{tabular}

Abstract 1075 Table 2

\begin{tabular}{|c|c|c|c|c|c|c|c|}
\hline & $\mathbf{G A}(w)$ & BW $(g)$ & Crib Score & 1st min Apgar & 5th min Apgar & Lowest $\mathrm{CO}_{2}(\mathrm{mmHg})$ & Highest $\mathrm{CO}_{2}(\mathrm{mmHg})$ \\
\hline $\mathrm{PHH}(+) n=9$ & $31(26-38)$ & $1715(866-3330)$ & $3(0-14)$ & $7(1-9)$ & $9(6-10)$ & $29(18-59)$ & $117(84-187)$ \\
\hline $\mathrm{PHH}(-) n=16$ & $34(24-40)$ & $1820(660-4000)$ & $2.5(0-11)$ & $7(1-9)$ & $9(3-10)$ & $28(16-43)$ & 65 (31-180) \\
\hline$p$ & 0.2 & 0.44 & 0.5 & 0.6 & 0.8 & 0.8 & 0.044 \\
\hline
\end{tabular}

